\title{
SMART WOVEN FABRICS WITH PORTABLE AND WEARABLE VIBRATING ELECTRONICS
}

\author{
Hakan Özdemir'1, Selçuk Kılınç² \\ 'Dokuz Eylül University, Textile Engineering Department, İzmir, Turkey, Tel: +90 23230177736 , \\ Fax: +90 232 3017750, Corresponding author e-mail: h.ozdemir@deu.edu.tr \\ ${ }^{2}$ Dokuz Eylül University, Electrical and Electronic Engineering Department, İzmir, Turkey, \\ Tel: +90 232 3017185, Fax: +90 232 4531085, e-mail: selcuk.kilinc@deu.edu.tr
}

\begin{abstract}
:
The portable and wearable instrumented fabrics capable of measuring biothermal variable is essential for drivers, especially long-distance drivers. Here we report on portable and wearable devices that are able to read the temperature of human body within the woven fabric. The sensory function of the fabric is achieved by temperature sensors, soldered on conductive threads coated with cotton. The presence of stainless steel wires gives these materials conductive properties, enabling the detection of human body temperature and transmitting the signal form sensors to the motors on the fabric. When body temperature decreases, hardware/software platforms send a signal to the vibration motors in order to stimulate the driver. The 'smart woven fabric'-sensing architecture can be divided into two parts: a textile platform, where portable and wearable devices acquire thermal signals, and hardware/ software platforms, to which a sensor sends the acquired data, which send the signals to the vibration motors.
\end{abstract}

\section{Keywords:}

Smart textile system, smart fabrics, portable electronic textiles, wearable electronic textiles, conductive yarns, vibrating

\section{Introduction}

Electronics have been implicated in the form of flexible wearable new applications for monitoring purposes, thanks to the technology miniaturisation and wireless revolution. A number of prototype garments that can monitor and relay various types of data have been developed as a result of ongoing research on wearable electronic systems [1].

A smart textile is able to "sense" changes in the environmental condition with a sensing function. A sensor is a device providing information, mostly in the form of an electrical signal. It perceives the measured object or medium and emits a signal related to the variations of the measured quantity [2]. The measured quantities are of various types, such as position, velocity, temperature, humidity, force, pressure and flow. Most signals are conveyed in the electrical form by sensors; therefore, using electro-conductive materials is the most efficient way to create a textile sensor. In turn, actuators in smart textiles react to a signal coming from the sensor or data-processing unit in the form of movement, noise, substance release and so on.

In order to function as a stand-alone unit, smart textiles require energy supply and energy storage capacity. Power supply technologies provide electrical power for the activation of other constituents of the smart textile system. In order to make multifunctional and interactive systems, the electronic components of a smart textile system must be linked on to each other by means of common physical materials such as wires, cables and connectors. Electro-conductive yarns are used as warp and/or weft yarns in woven fabrics to form a bus-like structure and carry out the interconnection or communication between different components of a smart textile system [3].

The main advantage of textiles is their flexibility, related in some aspects to clothing comfort. Woven fabrics are structurally convenient for wearable electronic clothing used for monitoring applications in such a way that woven fabrics provide dimensional stability and constructing circuits in a woven structure is less complicated because warp and weft yarns can be easier to control than a knitted structure. The interlacing of warp and weft in woven fabrics functions as networks for electrical circuits and as well as the supporting material for the integrated electronics [4].

Textile sensors are used for the recording of electrocardiogram (ECG), respiration rate, heart rate, and so on; Van Langenhove and Hertleer [5] developed textile electrodes that were made of stainless steel fibres and had a knitted structure for ECG and heart rate measurements. They were incorporated into a belt to be worn around the thorax. In the study of Loriga, Taccini, De Rossi, and Paradiso [6], conductive and piezo-resistive yarns were integrated in a knitted garment and used as sensor and electrode elements to monitor cardiopulmonary activity. Fabric electrodes were realised with a yarn in which a stainless steel wire was twisted around a cotton-based yarn. Catrysse et al. [7] developed a textile sensor called the "Respibelt" for measuring respiration. Made of a stainless steel yarn and knitted in a Lycra-containing belt, the belt was able to provide an adjustable stretch. Song et al. [8] developed jacquard fabricbased textile electrode made with silver covering yarn; it can be manufactured evenly with consistent properties. The convex type of $50 \%$ half removed warps of jacquard woven electrode 
with the conductive paste resulted in the most significant ECG signals for physiological monitoring.

There are other studies about portable and wearable electronic textiles; Mazzoldi et al. [9] developed wearable devices that are able to read and record the posture and movements of a subject wearing the system. Strips of strain fabrics were applied together with conductive tracks at strategic points in a shirt and a glove in order to detect the movements of the principal joints. Rossi et al. [10] developed the wearable devices (a smart shirt, a leotard and a glove) that can read and record the vital signals and movements of a subject wearing the system. The sensing function of the garments is based on piezo-resistive fabric sensors, based on carbon-loaded rubbers and different conductive materials.

The primary function of sleep is conserving the body energy, so less energy is used to keep the body temperature at certain level during sleep. Before sinking into sleep, the human body loses heat and the body temperature decreases $1-2^{\circ} \mathrm{F}(0.56-$ $1.11^{\circ} \mathrm{C}$ ) during sleep eventually [11]. The aim of this article is to present the driver vibrating textile-based system with temperature sensors that alerts the driver when he/she feels sleepy or sleeps. The major consideration at the starting point of circuit design is the thermal feedback from the users who are wearing these electronic textiles. After portable device with temperature indicator developed, wearable device, userfriendly, was created.

\section{Production of woven fabric}

$2 / 2$ twill woven fabrics are commonly used for men and woven shirts, so, in this research, $2 / 2$ twill woven fabric samples $(30 \times 30$ $\mathrm{cm}$ ) were produced in the in-house weaving workshop by $\mathrm{CCl}$ automatic sample rapier loom (Evergreen 8900, Taipei, Taiwan). Hundred percent polyester and stainless steel core yarns with cotton fibre as sheath material were used. The specifications of yarns are given in Table 1. While the electro-conductive and polyester yarns were inserted in 1-7 orders to obtain enough space between conductive yarns within the fabrics, only polyester yarns were used as warp yarns to disallow contact with conductive weft yarns. The open-parallel structure of the conductive yarns are represented with grey squares and letter $\mathrm{C}$, whereas the polyester yarns are represented with white squares and letter $P$ in Figure 1. Both white and grey squares also represent intersection points between warp and weft yarns. Warp and weft settings of woven fabric sample on the loom were $24 \mathrm{~cm}^{-1}$, which was calculated for the loom state. No finishing process was applied on the fabric samples.

Table 1. The specifications of yarns.

\begin{tabular}{|c|c|c|c|}
\hline Material & $\begin{array}{c}\text { Yarn } \\
\text { count } \\
\text { (dtex) }\end{array}$ & $\begin{array}{c}\text { Diameter } \\
\text { of wire } \\
\text { (mm) }\end{array}$ & $\begin{array}{c}\text { Conductor } \\
\text { resistance } \\
\mathbf{( \Omega m m 2 / m ) ~}\end{array}$ \\
\hline $\begin{array}{c}\text { Polyester } \\
\text { yarn }\end{array}$ & 600 & - & - \\
\hline $\begin{array}{c}\text { SS/Co core } \\
\text { yarn }\end{array}$ & 455 & 0.05 & 0.62 \\
\hline
\end{tabular}
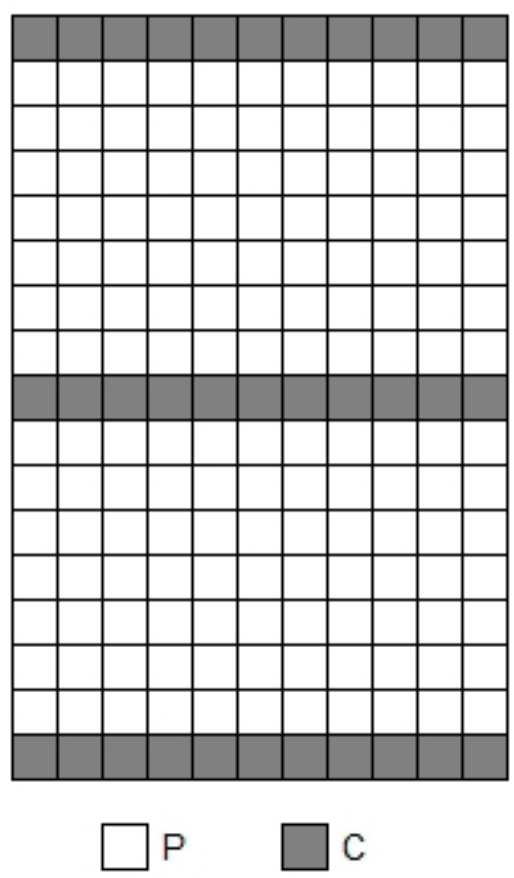

Figure 1. Schematic diagram of open-parallel structure formed in the woven fabrics (grey squares: electro-conductive core yarns; white squares: polyester yarns)

\section{Production of devices}

In order to measure the driver's body temperature and, at the same time, alert a driver when his/her temperature goes below a certain value (in our case $35.5^{\circ} \mathrm{C}$ ), two electronic devices have been designed within the frame of this study. One of them is a general-purpose portable device and the other one is a wearable device, which is much smaller than the previous one. In this section, we give the details of these electronic circuits.

\subsection{Portable device}

The circuit schematic of the portable device is shown in Figure 2. It consists mainly of a microcontroller (PIC16F628), a display, a programmable digital thermometer (DS18B20), a decade counter (4017), a relay, a vibration motor, several push-buttons and various resistors and transistors. The microcontroller is the most essential element of this circuit. It realises most of the job by means of the software embedded on it. User is able to set the temperature below which the motor will start vibrating to stimulate the driver. This setting is done through the pushbuttons. We adjusted this value as $35.5^{\circ} \mathrm{C}$. Body temperature is sensed by DS18B20, which should be placed on (or near to) the skin of the driver. The information about the temperature of the driver is acquired by the microcontroller, which sends this value to the display for monitoring the current temperature. For this purpose, 4017 decade counter and transistors are used in the circuit. In this way, one can continuously observe the body temperature of the driver on the display. The temperature is constantly sensed by the microcontroller and compared with the set value $\left(35.5^{\circ} \mathrm{C}\right)$ in every cycle of the software program running on the microcontroller. The software is constructed such that when the temperature goes below $35.5^{\circ} \mathrm{C}$, the $18^{\text {th }}$ 
terminal (pin18) of the microcontroller is made logic "1" (i.e. 5 volts). This terminal is connected to the transistor that activates the relay through a resistor. When this happens, the relay is activated and the motor stars vibrating to stimulate the driver.

A photograph of the implemented circuit together with the fabric is shown in Figure 3. The energy supply (voltage source), used in the circuit are $9 \mathrm{~V}$ batteries as they are easy to obtain. We used 7805 voltage regulator to convert this value to $5 \mathrm{~V}$, because of the necessity of $5 \mathrm{~V}$ voltage supply in the circuit. The three terminals of the DS18B20 digital thermometer are soldered on the conductive weft yarns of the fabric. The thermometer transmits the electrical information about the body temperature of the driver to the electronic device through these conductive weft yarns. In Figure 3, the digital thermometer is shown on the bottom left of the picture (the small black electronic component on the left edge of the fabric). The electrical signal generated by this element is transmitted (through the white conductive yarns) to the right edge of the fabric where the electronic device is placed.

\subsection{Wearable device}

The second circuit we designed for the purpose of stimulating the driver in the case of falling asleep is much smaller and simpler than the portable device. It occupies much less area; therefore, it is possible to sew it on the fabric that can be used for the clothes of the driver. For this reason, we call this circuit a wearable device, the schematic of which is shown in Figure 4.

The main component of this circuit is the analogue comparator (LM311). It compares the voltage levels applied to its inputs (pin2 and pin3) and produces a binary output (either "0" or "1") from $7^{\text {th }}$ terminal (pin7). If the voltage level at the $2^{\text {nd }}$ terminal is greater than that of the $3^{\text {rd }}$ terminal, the output will be logic "1", otherwise it will be logic "0". We used LM35 temperature sensor in the circuit. If it is supplied appropriately, one can acquire an electrical voltage that is proportional to the ambient temperature from its middle terminal. The middle terminal of the LM35 is connected to the $3^{\text {rd }}$ terminal of the LM311 comparator. We observed experimentally that when the temperature is around $35.5^{\circ} \mathrm{C}$, the voltage measured on the middle terminal

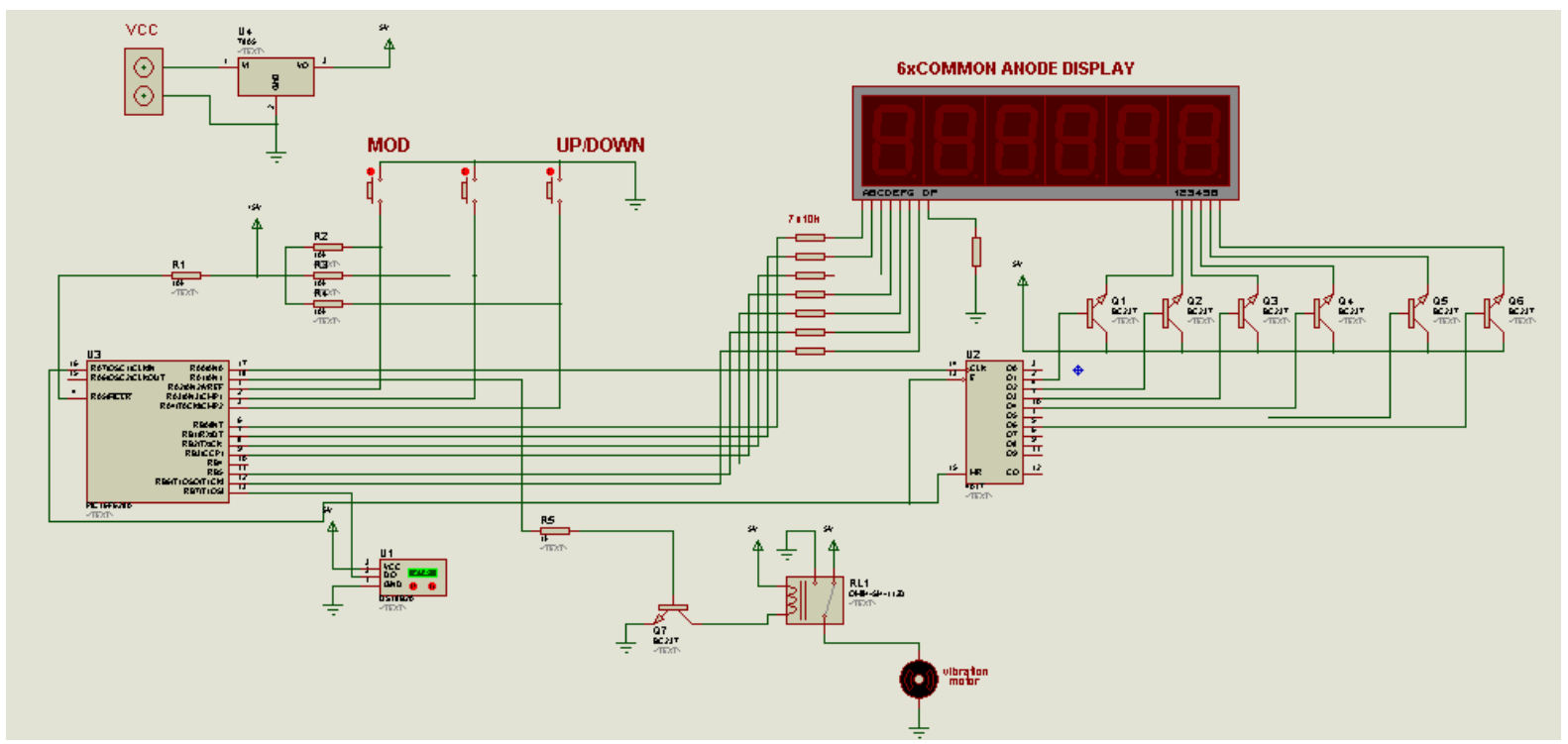

Figure 2. Schematic diagram of portable device

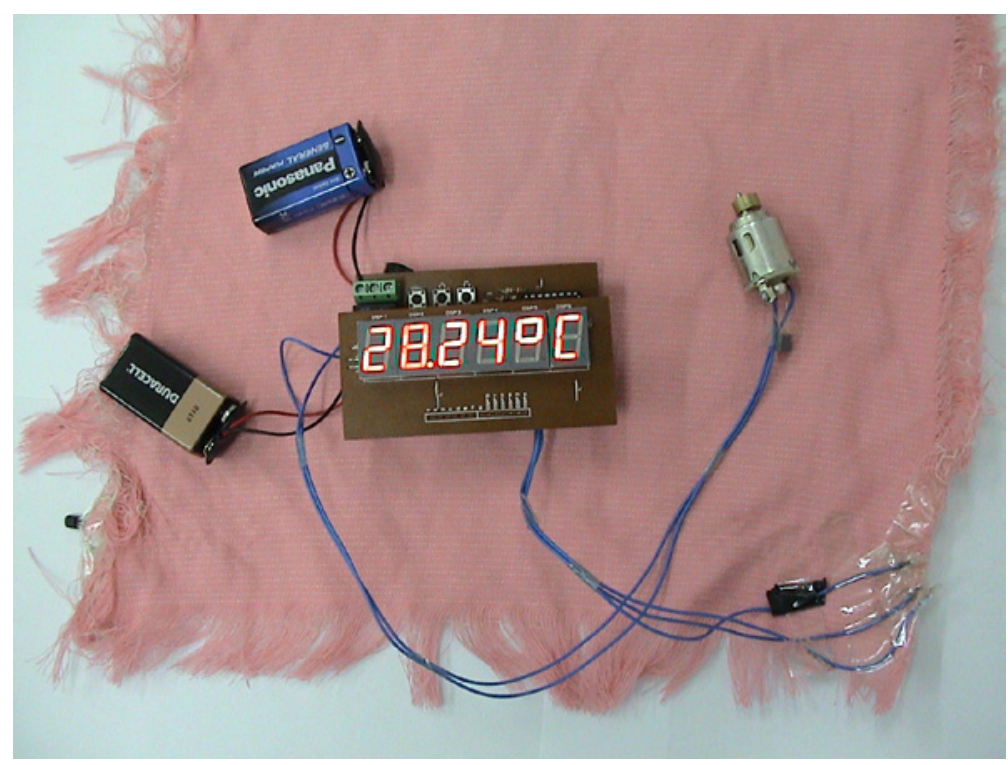

Figure 3. System with portable device 
of the temperature sensor is about $0.33 \mathrm{~V}$. A voltage divider is constructed using a resistor $(1 \mathrm{k} \Omega)$ and a variable resistor $(20 \mathrm{k} \Omega$ pot) to obtain a voltage level of $0.33 \mathrm{~V}$. This voltage is applied to the $2^{\text {nd }}$ terminal of the comparator. When the temperature is above $35.5^{\circ} \mathrm{C}$, the voltage at the negative input ( $3^{\text {rd }}$ terminal) of LM311 is greater than the voltage at its positive input $\left(2^{\text {nd }}\right.$ terminal). In this case, the output of the comparator becomes logic " 0 " that does not activate the transistor used for driving the vibration motor. When the temperature is below $35.5^{\circ} \mathrm{C}$, the output will become logic "1". This will make the transistor to pass current through the motor, and thus vibration will occur to stimulate the driver. A photograph of the wearable device is shown in Figure 5. Similar electrical connections to the conductive weft yarns of the fabric are made as explained for the portable device.

\section{Experimental results}

The implemented circuits are tested in the laboratory. First, the ambient temperature is increased by a heater to a normal body temperature level. As expected, the motor does not vibrate in this case. Then, the temperature is made lower than $35.5^{\circ} \mathrm{C}$, in which case, the motor starts vibrating.

The experimental results of the wearable device are illustrated in Figure 6, which shows two snapshots of an oscilloscope screen. The oscilloscope is a measuring device that is used for observing the voltage waveforms in electric circuits. In Figure $6(a)$, output voltage of the comparator for temperatures greater than $35.5^{\circ} \mathrm{C}$ is shown. As expected, the voltage is zero and thus the motor does not vibrate. When the temperature is less than $35.5^{\circ} \mathrm{C}$, the output voltage becomes $5 \mathrm{~V}$ as shown in Figure $6(\mathrm{~b})$, switching the motor on (each vertical division on the oscilloscope screen is adjusted to $5 \mathrm{~V}$ ).

\section{CONCLUSIONS}

While the human body temperature is $36.5^{\circ} \mathrm{C}$ at normal conditions, body temperature declines by $1-2^{\circ} \mathrm{C}$ when a person feels sleepy or sleeps. In this study, the portable and wearable devices were designed and integrated with woven fabrics by conductive core steel yarns in weft direction. Temperature

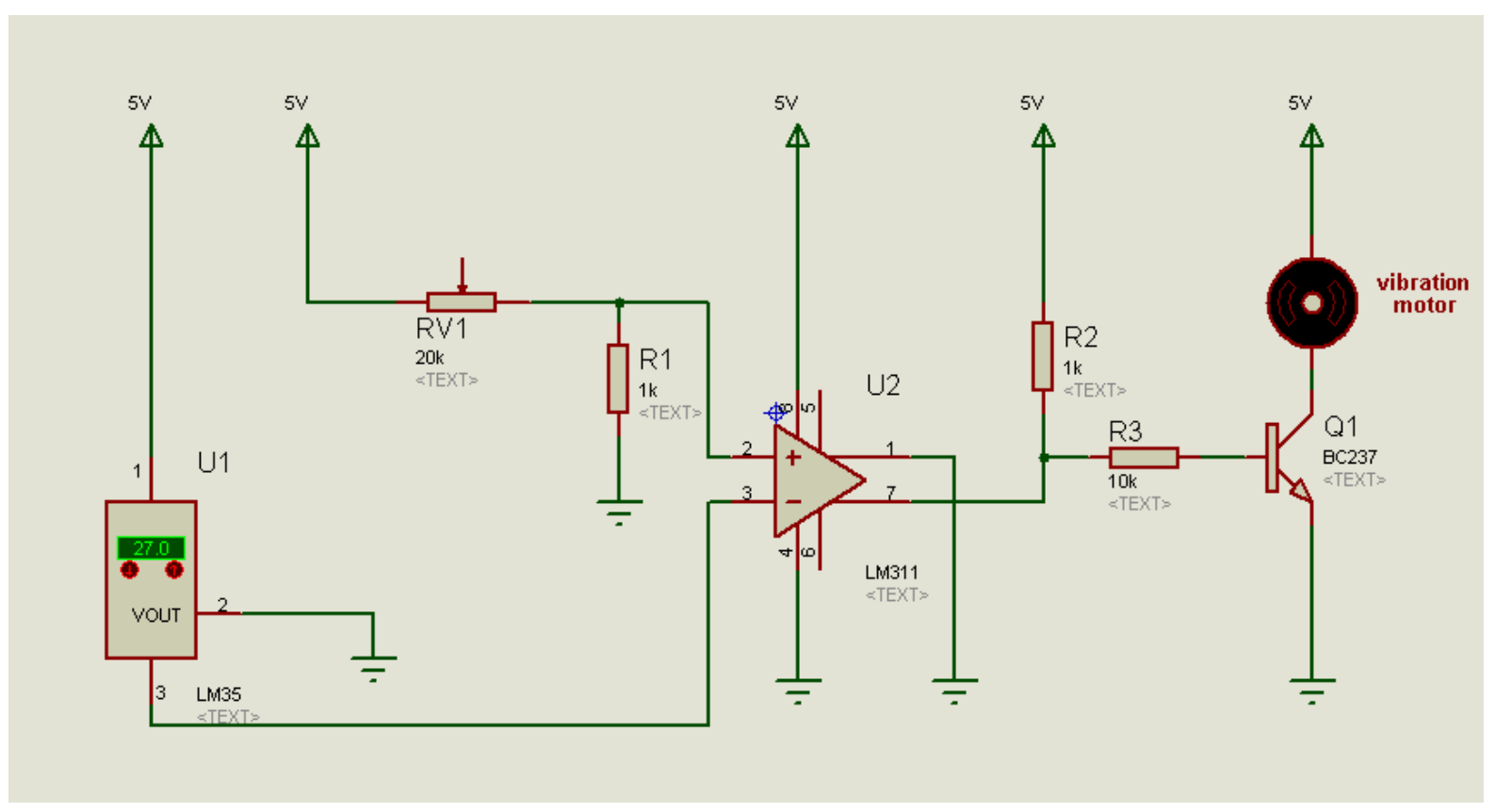

Figure 4. Schematic diagram of wearable device

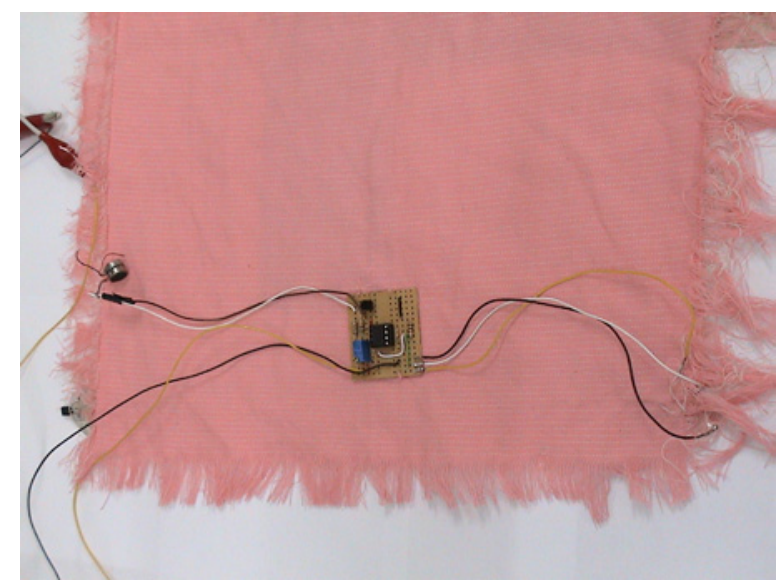

Figure 5. System with wearable device (the size of the electronic component is about $3 \times 4 \mathrm{~cm}$ ) 


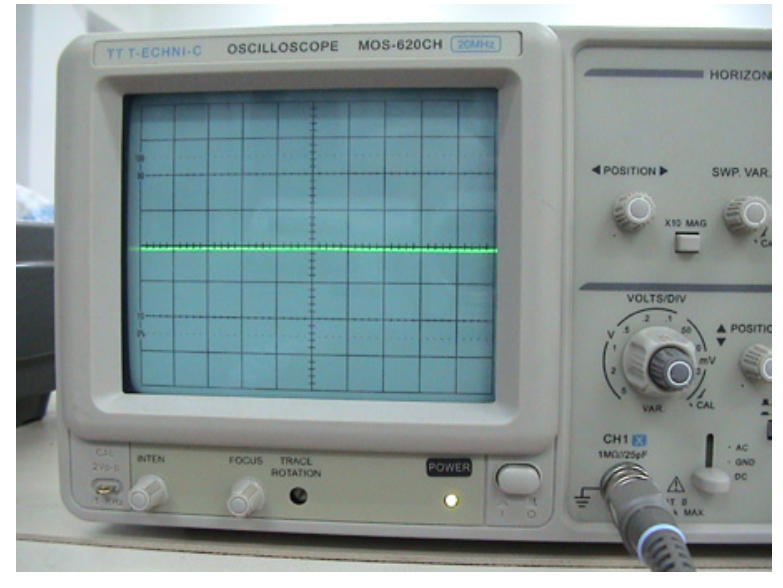

(a)

Figure 6. Experimental results of the wearable device

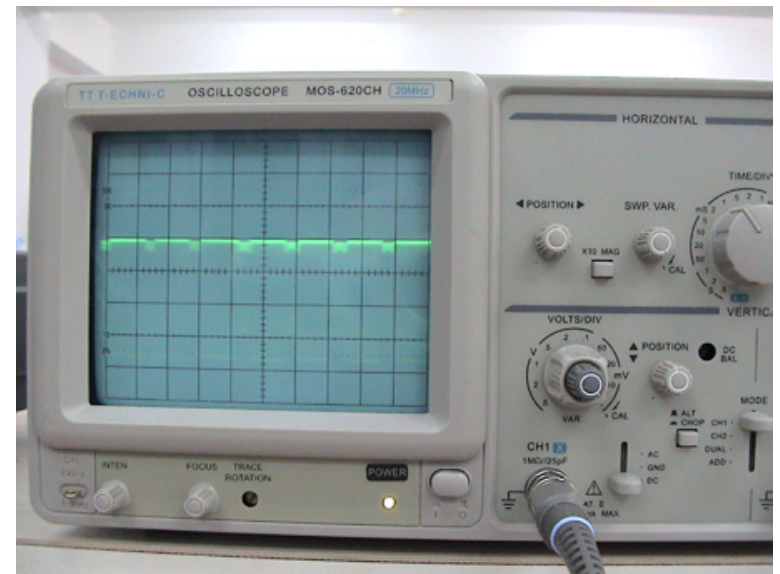

(b) sensors perceive body temperature and the conductive core yarns transmit the data. If the temperature decreases below $35.5^{\circ} \mathrm{C}$, the devices will start up the vibration motors.

Woven fabric has low strain properties and can be constructed more uniformly in both warp and weft directions. Therefore, due to their more consistent structure, woven fabrics made of conductive yarns can consistently maintain their properties. Consequently, the smart woven fabrics developed within the scope of this study can be used in smart clothes in order to stimulate and awaken the long-distance drivers.

\section{References}

[1] Tang, S.L.P.T. (2007). Recent developments in flexible wearable electronics for monitoring applications. Transactions of the Institute of Measurement and Control, 29, 283-300.

[2] Vassiliadis, S. (1996). Automation and the Textile Industry. Beigl, M., Intille, S., Rekimoto, J., Toknda, H. (Eds.). Educational Institution of Piraeus \& Guimaraes Universidade do Minho, (Greece).

[3] Schwarz, A., Van Langenhove, L., Guermonprez, P., Deguillemont, D. (2010). A roadmap on smart textiles. Textile Progress, 42(2), 99-180.

[4] Dhawan, A., Seyam, A.M., Ghosh, T.K. and Muth, J.F. (2004). Woven fabric-based electrical circuits. Part I:
Evaluating interconnect methods. Textile Research Journal, 74, 913-19.

[5] Van Langenhove, L., Hertleer, C. (2004). Smart clothing: a new life. International Journal of Clothing Science and Technology, 16(1/2), 63-72.

[6] Loriga, G., Taccini, N., De Rossi, D., Paradiso, R. (2005). Textile sensing interfaces for cardiopulmonary signs monitoring. Proceedings of the 2005 IEEE Engineering in Medicine and Biology 27 $7^{\text {th }}$ Annual Conference, 7349-7352.

[7] Catrysse, M., Puers, R., Hertleer, C., Van Lagenhove, L., van Egmond, H., Matthys, D. (2004). Towards the integration of textile sensors in a wireless monitoring suit. Sensors and Actuators A, 114, 302-311.

[8] Song, H.Y., Lee, J.H., Kang, D., Cho, H., Cho, H.S., Lee, J.W., Lee, Y.J. (2010) Textile electrodes of jacquard woven fabrics for biosignal measurement. The Journal of the Textile Institute, 101(8), 758-770.

[9] Mazzoldi, A., Rossi, D.D., Lorussi, F., Scilingo, E.P., Paradiso, R. (2002). Smart textiles for wearable motion capture systems. AUTEX Research Journal, 2,(4), 199203.

[10] Rossi, D.D., Carpi, F., Lorussi, F., Mazzoldi, A., Paradiso, R., Scilingo, E.P., Tognetti, A. (2003). Electroactive fabrics and wearable biomonitoring devices. AUTEX Research Journal, 3(4), 180-185.

[11] http://healthysleep.med.harvard.edu/healthy/science/ what/characteristics, 18.07.2014 